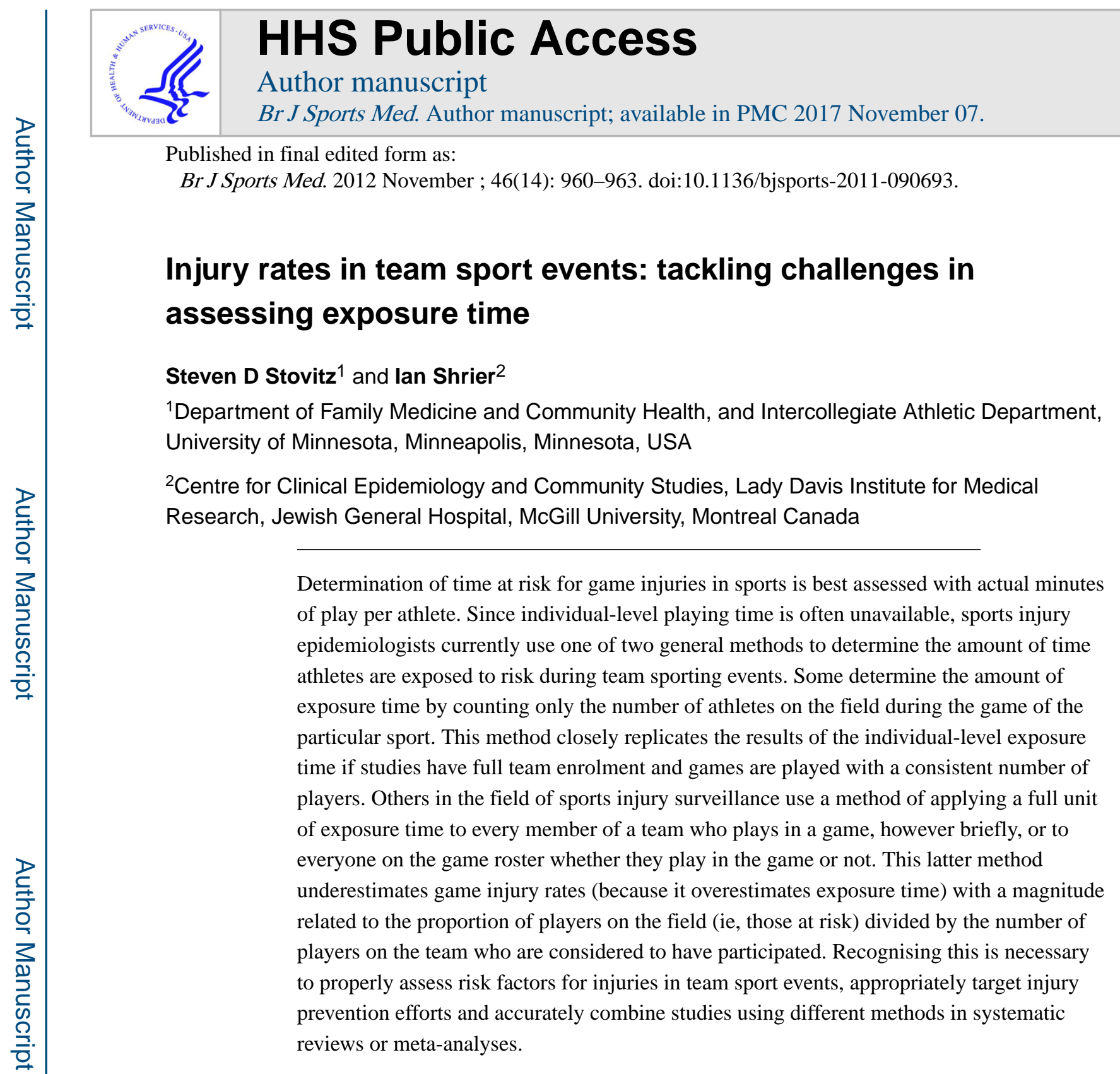

\title{
INTRODUCTION
}

In epidemiology, incidence rate is calculated as the number of events divided by some unit of person time for a population at risk. ${ }^{1}$ In assessing injury rates during team sporting events, sports teams are dynamic cohorts where athletes are exposed to game-time injury risk only when on the playing field. Assuming no other problems with the study methodology, the unbiased estimate for injury rates is calculated using individual-level data for injuries and exposure times, ${ }^{1-5}$ and a statistical model that is appropriate for the underlying data distribution and heterogeneity of the injury rates (eg, Poisson, negative

Correspondence to Steven D Stovitz, Department of Family Medicine and Community Health, and Intercollegiate Athletic Department, University of Minnesota, 717 Delaware St. SE, Minneapolis, MN 55414, USA; sstovitz@ umphysicians.umn.edu.

Contributors SDS and IS contributed equally to the manuscript's concept, analysis, writing and editing.

Competing interests None.

Provenance and peer review Not commissioned; externally peer reviewed. 
binomial, quasi-Poisson). ${ }^{6}$ These data can be used to (1) answer general questions such as overall injury rates per game or per hour of game play, (2) investigate specific risk factors for injury by including individual-level covariates (eg, athlete's age, previous injury) or (3) calculate quantile injury rates that answer questions like 'what is the probability that a player will have three or fewer injuries?'

Although calculations using individual-level exposure time is optimal, capturing exact minutes of play may be difficult or impossible, such as with investigations at the high school level or in large, central source databases. In such cases, risk factor analysis based on athlete-level characteristics becomes extremely problematic. However, it remains possible to assess overall injury rates and risk factors if one estimates the time of exposure at the team level. Here, sports injury epidemiologists have used different methods to quantify exposure time. As with any study of incidence rates, different choices for the denominator in the rate calculation may be a necessary consequence of the particular research question ${ }^{37}$ (eg, injuries per minute of play vs injuries per game of play). However, a commonly used method in sports injury surveillance studies leads to a systematic under-representation of game injury rates as it overestimates the time at risk. This bias is especially apparent when comparing injury rates across sports and may alter the comparison of injury rates between games and practices within single sports.

The purpose of this study is to compare and contrast injury rates calculated via two common methods for estimating game exposure time when individual-level data are unavailable. This will be shown first through a theoretical example, and then through a re-analysis of published data on three US collegiate women's sports.

\section{THEORETICAL EXAMPLE}

Imagine that you want to compare game-time injury rates between a University's soccer team and hockey team. For illustrative purposes, we assume that the soccer games are all played for 90 min with 11 players on the field, and 5 players on the bench who play for a small portion of the game as replacements (16 players on the team participate). The hockey games are played for 60 min with six players on the ice and 10 players on the bench (again, 16 players participate). We also assume that teams play with a constant number of players (ie, no penalties); each sport has a 20 game season and each team has four injuries.

\section{ATHLETES AT RISK METHOD}

One method to estimate team-level exposure time uses the number of players on the field multiplied by either the number of games or the number of game-hours that the team has played. ${ }^{2458-14}$ Using the soccer scenario above, there are 11 athletes at risk (AAR) on the field at any one moment during the games. With four injuries over the 20 game season, the game injury rate for soccer is $4 /(11 \times 20)=0.0182$ injuries per athlete-game (usually expressed as 18.2 injuries per 1000 athlete-games). For hockey, there are six AAR, that is, on the ice, at any one moment. With four injuries, the hockey game injury rate is 33.3 injuries per 1000 athlete-games, that is, 1.8 times that of soccer. If one were interested in the injury rate per hour of game exposure, the injury rate for soccer would be 12.1 per 1000 game-hours 
because the games last $1.5 \mathrm{~h}$. For hockey, the injury rate would be 33.3 per 1000 game-hours because the games last $1 \mathrm{~h}$. When games are played with a consistent and predictable number of players and do not go into overtime, then this method replicates the results obtained from summing the actual game minutes played at the team level. However, this method will overestimate exposure time in games where penalties reduce the number of players on the field for part of the game (eg, red cards in soccer and penalties in hockey), and underestimate exposure time if games go into overtime and this extra time is not counted.

\section{ATHLETE PARTICIPATION METHOD}

Another method published in high-quality journals uses 'athlete exposures' ${ }^{15}$ which refers to 'one athlete participating in one practice or game', ${ }^{16}$ or some close variation. Within this definition, 'participation' is sometimes defined as those who actually played in the games, ${ }^{16-18}$ and sometimes as those on the game roster whether they played or not. ${ }^{19-23} \mathrm{We}$ therefore will use the term 'athlete participation (AP)', and not replicate the term 'exposure'. Here, all participating athletes are counted equally even though exposure time ranges from full to partial to, potentially, none. The result is that the AP method consistently overestimates total athlete exposure time at risk, and hence underestimates injury rates. With this method, the magnitude of the bias will depend upon the ratio of the number of athletes on the field at any one time (ie, the athletes at risk), to the number of athletes who 'participated' in the game.

Returning to our theoretical example, soccer and hockey had 16 players who participated for some portion of the 20 games and had four injuries. Thus, analysing the players who 'participated' as a closed cohort, the calculated injury rate per 1000 athlete-games would be $(1000 \times 4) /(16 \times 20)=12.5$ injuries per 1000 athlete-games for both sports. This represents a $31.3 \%$ underestimate for soccer (recall, soccer had a rate of 18.2) and a $62.5 \%$ underestimate for hockey (hockey had a rate of 33.3). Injury rates expressed per 1000 game-hours would have the same proportional bias as per 1000 athlete-games because the estimates of exposure time in the unbiased (using individual-level exposure time, or AAR under specific conditions) and biased (using AP) methods in soccer are divided 1.5 (ie, $1.5 \mathrm{~h}$ per game), and those for hockey are divided by 1 (ie, $1 \mathrm{~h}$ per game).

\section{EMPIRICAL EXAMPLE OF THE EFFECTS OF TWO COMMONLY USED METHODS FOR ASSESSING EXPOSURE TIME}

To highlight the effects of the AAR and AP exposure time definitions, we discuss published results obtained from analyses of the National Collegiate Athletic Association (NCAA) injury surveillance system for three major US intercollegiate women's sports: soccer, hockey and basketball. ${ }^{24-26}$ The injuries and participants were recorded by athletic trainers at participating Universities between the years 1988 and 2004. ${ }^{27}$

In table 1, Part A, we show the extracted data for injuries and games within each sport. ${ }^{24-26}$ Because the published reports had rounded the number of players participating in the games for each sport to whole numbers, ${ }^{24-26}$ we recalculated the number of players participating 
using the number of injuries divided by the product of reported injury rates and number of games.

\section{Injury rates per 1000 athlete-games}

In table 1, part B, we compare the injury rates per 1000 athlete-games using the AAR and AP methods (note: the publications on the NCAA data used the number of players who actually entered the game as their AP definition). ${ }^{27}$ The calculated injury rates using the AP method are consistently lower than the injury rates using the athletes at risk method because the AP method overestimates the at-risk exposure times. Assuming the AAR method is unbiased compared with the individual level-exposure time method, the AP method captures $69 \%$ of the true injury rate in soccer (16.4/23.9), 34\% in hockey (12.6/37.3) and 49\% in basketball (7.7/15.7). These percentages are equal to the proportion of AAR to 'athletes participating' in the respective sports (shown in table 1, part A, fifth row).

It is also possible to compare the AAR and AP methods for rate ratios across sports (we used soccer as the reference). The AP method used in the published reports suggested that hockey players have a lower injury rate than soccer players (rate ratio=0.77). However, the AAR method reveals that hockey players actually had a higher injury rate (rate ratio=1.56). ${ }^{16}$ The ratio of these rate ratios (1.56/0.77) is equal to the proportion of AAR to 'athletes participating' in the respective sports of hockey and soccer (see table 1, part A, row 5, ie, 0.69/0.34). This easy conversion should allow future authors of meta-analyses and systematic reviews to make the appropriate adjustments when necessary.

\section{Injury rates per 1000 athlete game-hours}

Table 1 part $\mathrm{C}$ compares the AAR and AP methods for injury rates per 1000 athlete gamehours. This addresses a different research question and was not analysed in the original published reports using the NCAA data, ${ }^{24-26}$ although it has been reported by others. ${ }^{8-11}$ In the context of team sports, many are likely interested in injury risk per game, because athletes think of playing full games regardless of length. However, for certain sports such as running, one might be more interested in injuries per unit time because keeping all other risk factors constant, one would expect more injuries running for $10 \mathrm{~km}$ versus $5 \mathrm{~km}$ simply due to increased time at risk. Because basketball games last only $40 \mathrm{~min}$ and soccer games last $90 \mathrm{~min}$, assessment by athlete game-hours changes the injury rate rankings and basketball now appears to have a higher injury rate than soccer (47\% higher using the AAR method, $6 \%$ higher using the AP method).

\section{Injury rate ratios in games compared with practices}

Table 1 part D illustrates the result of the AAR and AP methods when comparing injury rates per 1000 athlete-games (shown in part B) with 1000 athlete practices (shown on the last row of part A). Numerous studies have found injury rates in games to be higher than in practices. ${ }^{10111628}$ Of note, counting all team members for practice injury rates is expected to be relatively accurate because all athletes on a team are generally exposed during most of the practice, and thus at risk for injury. Therefore, the amount of bias in the game:practice injury rate ratio calculated using the $\mathrm{AP}$ or $\mathrm{AAR}$ method mimics the bias in the calculated game injury rate. Analysing the information from the NCAA database for women's hockey, the 
game to practice injury rate ratio using the AAR method is 14.9 , whereas the published AP method calculated rate ratio is 5.25

\section{CAVEATS}

We have assumed that studies involve entire teams. If team recruitment is incomplete (ie, if less than $100 \%$ of the team members participate in the study), then bias will occur if enrolment is associated with playing time or risk-taking behaviours or both. For sports played without a clock (eg, baseball, volleyball and gymnastics), the choice of the denominator (eg, per 1000 innings, per 1000 games, per 1000 events) depends on the research question. We defined 'at risk' as being on the field during game time. We consider an injury during warm-ups of a game to be more consistent with a practice-related injury. However, others might view this as a game-related injury. It is possible, albeit rare, for athletes to be injured in a game when not on the field. Although the AP method captures these athletes in the denominator and the AAR method does not, injuries on the bench are not a major focus of sports injury prevention. Some may be interested in questions such as 'what is the probability of injury to an athlete on a team during a game?' In this case, the answer is a proportion (sometimes restricted to the word 'risk'), and not a 'rate' (which includes a component of time). ${ }^{3}$ Here, the AP method using all the players on the game roster most accurately defines exposure as the focus is 'an athlete on a team during a game' and not the risk of playing the sport during a game. However, the AP method would still have serious limitations for comparisons between teams, as teams within sports may have different numbers of members.

The analysis of individual-level risk factors for injury (eg, previous injury) is severely limited with the AAR and AP methods. Although data from the AAR method could be used to assess time-independent risk factors (eg, rate ratios for forward vs defense in hockey) one at a time, multiple regression is only possible using an ecological analysis (ie, risk factor variables are recorded as proportion of team members having certain characteristics). Although multiple regression analysis from the AP method could be applied if the data are gathered and stored appropriately (eg, each row representing one athlete with total number of exposures, total number of injuries and columns for each risk factor characteristic), the yes/no categorisation of exposure for a particular game makes interpretation very difficult. Therefore, we strongly recommend that any multiple regression analysis for individual-level risk factor analysis be restricted to data that includes individual-level exposure time data. We recognise that collection of individual-level data is too cumbersome and costly for many studies of sports injury surveillance. However, there is simply too much risk in making inappropriate interpretations based on incomplete data.

The sport of US football raises unique questions, especially if compared with other sports. Although it is played with a clock, most of the time is spent between plays, and the number of plays differs greatly between teams of different playing styles. Thus, unlike other sports, time of play may be a less interesting denominator than number of plays. Unlike other team sports, in US football each position plays for approximately half the game. A game consists of essentially two contests: one between a team's offense $(n=11)$ and the other team's defense $(n=11)$, and vice versa. Full play at one position is only partial game exposure time. 
In this context, the AAR method can calculate unbiased overall injury rates, and compare offensive versus defensive injury rates as long as data are collected for offense and defense in each game. This is because there are always an equal number of offensive and defensive athletes on the field at any one time, and therefore no bias is introduced. However, if data were not collected on both teams within each game, then one would need to know the time (or number of plays) on offense or defense per game. If one were interested in comparing injury rates per position, one needs additional information on exposure time per position (eg the number of offensive wide receivers on the field changes from play to play). These issues related to risk factor analysis based on position may be pertinent to many sports, but likely more so with football given the large number of positions, and the fact that teams change the number of players at different positions often.

Finally, our discussion has focused on issues related to exposure time for sports injury epidemiology. Readers are referred elsewhere for a more complete discussion of other important issues applicable to all of injury epidemiology such as defining injury and measurement error, ${ }^{7}$ sufficient and component causes, ${ }^{7}$ or analytical issues such as proportions of injuries with numerator only data, ${ }^{6}$ multiplicity ${ }^{67}$ and heterogeneity. ${ }^{6}$

\section{SUMMARY}

Recording exact amounts of exposure time in sport events is overly cumbersome for many sports injury surveillance projects. When individual-level data are unavailable, sports injury epidemiologists currently use one of two main methods to assess overall exposure time. The AAR method includes only the number of athletes at risk on the field during the respective sporting events. This method closely replicates the results of the individual-level exposure time calculations if studies have full team enrolment and games are played with a consistent number of players. In contrast, the AP method applies a full unit of exposure time to everyone who plays in a game, however briefly, or to everyone on the game roster whether they participate or not. Consequently, the AP method underestimates game injury rates (because it overestimates exposure time) with a magnitude related to the proportion of players on the field (ie, those at risk) divided by the number of players on the team who are considered to have participated. Recognising this is necessary to properly assess risk factors for injuries in team sport events, appropriately target injury prevention efforts and accurately combine studies using different methods in systematic reviews or meta-analyses.

\section{Acknowledgments}

The authors would like to thank Karim Khan, $\mathrm{MD}, \mathrm{PhD}$, and Logan Spector, $\mathrm{PhD}$, for their careful reading and comments on a preliminary draft of this manuscript.

Funding Steven D Stovitz was funded by a career research training grant from the US National Institutes of Health (5K12-RR023247-04) and Ian Shrier was funded by the Lady Davis Institute for Medical Research in Canada.

\section{References}

1. Szklo, M., Nieto, FJ. Epidemiology: beyond the basics. Sudbury, Mass: Jones and Bartlett Publishers; 2007. p. 48-71.

2. Lindenfeld TN, Noyes FR, Marshall MT. Sports injury research. Components of injury reporting systems. Am J Sports Med. 1988; 16(Suppl 1):S69-80. [PubMed: 3414891] 
3. Knowles SB, Marshall SW, Guskiewicz KM. Issues in estimating risks and rates in sports injury research. J Athl Train. 2006; 41:207-15. [PubMed: 16791309]

4. Fuller CW, Ekstrand J, Junge A, et al. Consensus statement on injury definitions and data collection procedures in studies of football (soccer) injuries. Br J Sports Med. 2006; 40:193-201. [PubMed: 16505073]

5. Fuller CW, Dick RW, Corlette J, et al. Comparison of the incidence, nature and cause of injuries sustained on grass and new generation artificial turf by male and female football players. Part 1 : match injuries. Br J Sports Med. 2007; 41(Suppl 1):i20-6. [PubMed: 17646246]

6. Shrier I, Steele RJ, Hanley J, et al. Analyses of injury count data: some do's and don'ts. Am J Epidemiol. 2009; 170:1307-15. [PubMed: 19812230]

7. Cummings P, Koepsell T, Mueller B. Methodological challenges in injury epidemiology and injury prevention research. Annu Rev Public Health. 1995; 16:381-400. [PubMed: 7639878]

8. Lindenfeld TN, Schmitt DJ, Hendy MP, et al. Incidence of injury in indoor soccer. Am J Sports Med. 1994; 22:364-71. [PubMed: 8037278]

9. Junge A, Dvorak J, Graf-Baumann T, et al. Football injuries during FIFA tournaments and the Olympic Games, 1998-2001: development and implementation of an injury-reporting system. Am J Sports Med. 2004; 32:80S-9S. [PubMed: 14754863]

10. Dvorak J, Junge A, Derman W, et al. Injuries and illnesses of football players during the 2010 FIFA World Cup. Br J Sports Med. 2011; 45:626-30. [PubMed: 21257668]

11. King DA, Hume PA, Milburn PD, et al. Match and training injuries in rugby league: a review of published studies. Sports Med. 2010; 40:163-78. [PubMed: 20092367]

12. Pinto M, Kuhn JE, Greenfield ML, et al. Prospective analysis of ice hockey injuries at the Junior A level over the course of one season. Clin J Sport Med. 1999; 9:70-4. [PubMed: 10442620]

13. Brooks JH, Fuller CW. The influence of methodological issues on the results and conclusions from epidemiological studies of sports injuries: illustrative examples. Sports Med. 2006; 36:459-72. [PubMed: 16737340]

14. Youn J, Sallis RE, Smith G, et al. Ocular injury rates in college sports. Med Sci Sports Exerc. 2008; 40:428-32. [PubMed: 18379203]

15. Clarke KS, Buckley WE. Women's injuries in collegiate sports. A preliminary comparative overview of three seasons. Am J Sports Med. 1980; 8:187-91. [PubMed: 7377451]

16. Hootman JM, Dick R, Agel J. Epidemiology of collegiate injuries for 15 sports: summary and recommendations for injury prevention initiatives. J Athl Train. 2007; 42:311-19. [PubMed: 17710181]

17. Deitch JR, Starkey C, Walters SL, et al. Injury risk in professional basketball players: a comparison of Women's National Basketball Association and National Basketball Association athletes. Am J Sports Med. 2006; 34:1077-83. [PubMed: 16493173]

18. Elliott MC, Zarins B, Powell JW, et al. Hamstring muscle strains in professional football players: a 10-year review. Am J Sports Med. 2011; 39:843-50. [PubMed: 21335347]

19. Emery CA, Kang J, Shrier I, et al. Risk of injury associated with body checking among youth ice hockey players. JAMA. 2010; 303:2265-72. [PubMed: 20530780]

20. Knowles SB, Marshall SW, Bowling JM, et al. A prospective study of injury incidence among North Carolina high school athletes. Am J Epidemiol. 2006; 164:1209-21. [PubMed: 17012366]

21. Kerr ZY, Collins CL, Pommering TL, et al. Dislocation/ separation injuries among US high school athletes in 9 selected sports: 2005-2009. Clin J Sport Med. 2011; 21:101-8. [PubMed: 21358499]

22. Rechel JA, Collins CL, Comstock RD. Epidemiology of injuries requiring surgery among high school athletes in the United States, 2005 to 2010. J Trauma. 2011; 71:982-9. [PubMed: 21986739]

23. Gessel LM, Fields SK, Collins CL, et al. Concussions among United States high school and collegiate athletes. J Athl Train. 2007; 42:495-503. [PubMed: 18174937]

24. Dick R, Putukian M, Agel J, et al. Descriptive epidemiology of collegiate women's soccer injuries: National Collegiate Athletic Association Injury Surveillance System, 1988-1989 through 20022003. J Athl Train. 2007; 42:278-85. [PubMed: 17710177] 
25. Agel J, Dick R, Nelson B, et al. Descriptive epidemiology of collegiate women's ice hockey injuries: National Collegiate Athletic Association Injury Surveillance System, 2000-2001 through 2003-2004. J Athl Train. 2007; 42:249-54. [PubMed: 17710173]

26. Agel J, Olson DE, Dick R, et al. Descriptive epidemiology of collegiate women's basketball injuries: National Collegiate Athletic Association Injury Surveillance System, 1988-1989 through 2003-2004. J Athl Train. 2007; 42:202-10. [PubMed: 17710168]

27. Dick R, Agel J, Marshall SW. National Collegiate Athletic Association Injury Surveillance System commentaries: introduction and methods. J Athletic Train. 2007; 42:173-82.

28. Shankar PR, Fields SK, Collins CL, et al. Epidemiology of high school and collegiate football injuries in the United States, 2005-2006. Am J Sports Med. 2007; 35:1295-303. [PubMed: 17369559] 
Table 1

Comparison of injury rates across three different women's sports based on reports using the National Collegiate Athletic Association (NCAA) Injury Surveillance System²4-26

\begin{tabular}{|c|c|c|c|}
\hline & Soccer & Hockey & Basketball \\
\hline \multicolumn{4}{|l|}{ Part A: from published data ${ }^{21-23}$} \\
\hline Game injuries * & 5373 & 264 & 3556 \\
\hline Games * & 20,447 & 1180 & 45,295 \\
\hline Athletes at risk $\left(\mathrm{AAR}^{\dagger}\right)$ & 11 & 6 & 5 \\
\hline Athletes participating $\left(\mathrm{AP}^{* * t}\right)$ & 16.0 & 17.8 & 10.2 \\
\hline (Athletes at risk)/(athletes participating) & 0.69 & 0.34 & 0.49 \\
\hline Game time (Hours) & 1.50 & 1.00 & 0.67 \\
\hline Practice injury rates (per 1000 athlete practices) ${ }^{*}$ & 5.2 & 2.5 & 4.0 \\
\hline
\end{tabular}

Part B: injury rates per 1000 athlete-games (rate ratio across sports $\mathcal{S}$ )
$\mathrm{AAR}^{\dagger}$ method
$23.9(1.00)$
$37.3(1.56)$
$15.7(0.66)$
AP $*$ method
$16.4(1.00) \quad 12.6(0.77) \quad 7.7(0.47)$

Part C: injury rates per $1000 \mathrm{~h}$ of athlete-game-hours (rate ratio across sports $\mathcal{S}$ )
$\mathrm{AAR}^{\dagger}$ method
$15.9(1.00) \quad 37.3(2.35)$
$23.4(1.47)$
AP ${ }^{*}$ method
$10.9(1.00) \quad 12.6(1.16) \quad 11.5(1.06)$

Part D: injury rate ratio for games versus practice *

\begin{tabular}{llll}
$\mathrm{AAR}^{\dagger}$ method & 4.6 & 14.9 & 3.9 \\
$\mathrm{AP}^{*}+$ method & 3.2 & 5.0 & 1.9 \\
\hline
\end{tabular}

Taken from publications using the National Collegiate Athletic Association (NCAA) injury surveillance system.

t

AAR, athletes at risk. The number of athletes at risk is the number of athletes on the playing field at any one time since these are the only athletes actually at risk of being injured.

F athletes on the roster (eligible to play in the game). The reports from the NCAA data used athletes who played in the games 27 and provided whole numbers only. ${ }^{24-26}$ The numbers in the table represent average values calculated by dividing the number of injuries by the product of the reported injury rate and number of games.

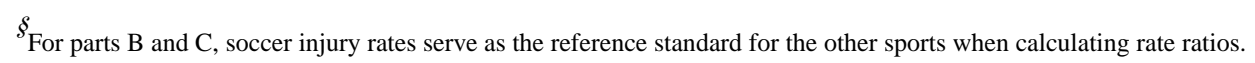

Br J Sports Med. Author manuscript; available in PMC 2017 November 07. 